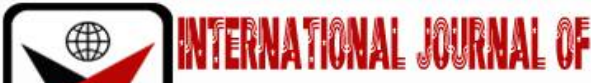

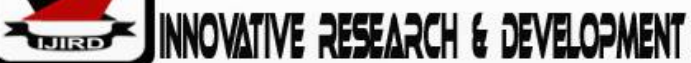

ISSN 2278-0211 (Online)

\section{Simulation Model of Silica Scale in Geothermal Wells: Case Study}

\author{
Dr. Herianto \\ Head, Engineering Department of Petroleum, UPN “Veteran” Yogyakarta, Indonesia
}

\begin{abstract}
:
Silica deposition in geothermal wells is one of the causes of the decline in geothermal production. Fluid from the seservoir that has been saturated by silica flows in the wellbore and begins to become two phases. This scale deposition occurs due to the flashing process in geothermal wells where hot water turns phase into steam in the wellbore. silica deposition occurs in several wells. From the results of the geochemical analysis of R-5 wells in May 2014, the SiO2 concentration of production fluid was $639.36 \mathrm{ppm}$, Cl concentration of $16875 \mathrm{ppm}$, and silica saturated index (SSI) of the $R-5$ well reached 1.78. Silica deposition can occur because of the reboiling and condensation processes as well as the flashing process. Pressure and temperature data from running PTS only present qualitative data from the fluid phase and do not present complete quantitative data from the fluid regime. Therefore, to determine flow regime and the rate of deposition of the scale, the CMG-Stars software is used.
\end{abstract}

Keywords: Silica Scale, CMG-STARS Simulation, Modelling

\section{Introduction}

R-5 well has a total drilling depth of $2306 \mathrm{~m}-\mathrm{Md}$ with a production initial of $52 \mathrm{~kg} / \mathrm{s}$. During the 6 months of production since 2009 this well decreased production to $24 \mathrm{~kg} / \mathrm{s}$ from initial production with a decline of $20.93 \%$. This well was previously carried out a well washing project (condensate injection) in 2012 with an increase in production of approximately 6 and $5 \mathrm{~kg} / \mathrm{s}$ respectively. However, not long after the production back down. Therefore, an analysis of formation water was carried out and it was found that the well was indicated to have silica scaling.

This scale deposition occurs due to the flashing process in geothermal wells where hot water turns phase into steam in the wellbore. In this field, silica deposition occurs in several wells. Silica deposition can occur because of the reboiling and condensation processes as well as the flashing process. The process of flashing in 2 phase wells occurs because of the loss of pressure and temperature in well. Fluid properties in a well, 1 phase or 2 phases are difficult to model or predict. Pressure and temperature data derived from running PTS only present qualitative data from the fluid phase and do not present complete quantitative data from the fluid regime. Therefore, to determine flow regime the CMG-Stars software is used. This approach requires a complex process to build simulators with several features found in CMG software. In this software, the initial input is reservoir and production data that can represent the actual condition of the well.

\section{Research Methodology}

The methodology used in this study began by collecting R-5 well data in the form of well diagram data and well history, then PTS (Pressure Temperature Spinner) running results at the time of initial well conditions, because at the time of the initial conditions there were no depositional scale. Historical data on actual and theoretical well production is also needed for the history matching process when conducting simulations. The theoretical production history data is used to build a well model and adjust well conditions if there is no scaling problem, while actual data is needed to match the normal well production rate and when the well flow rate is affected by silica deposits which reduces the diameter of the liner and well casing. 


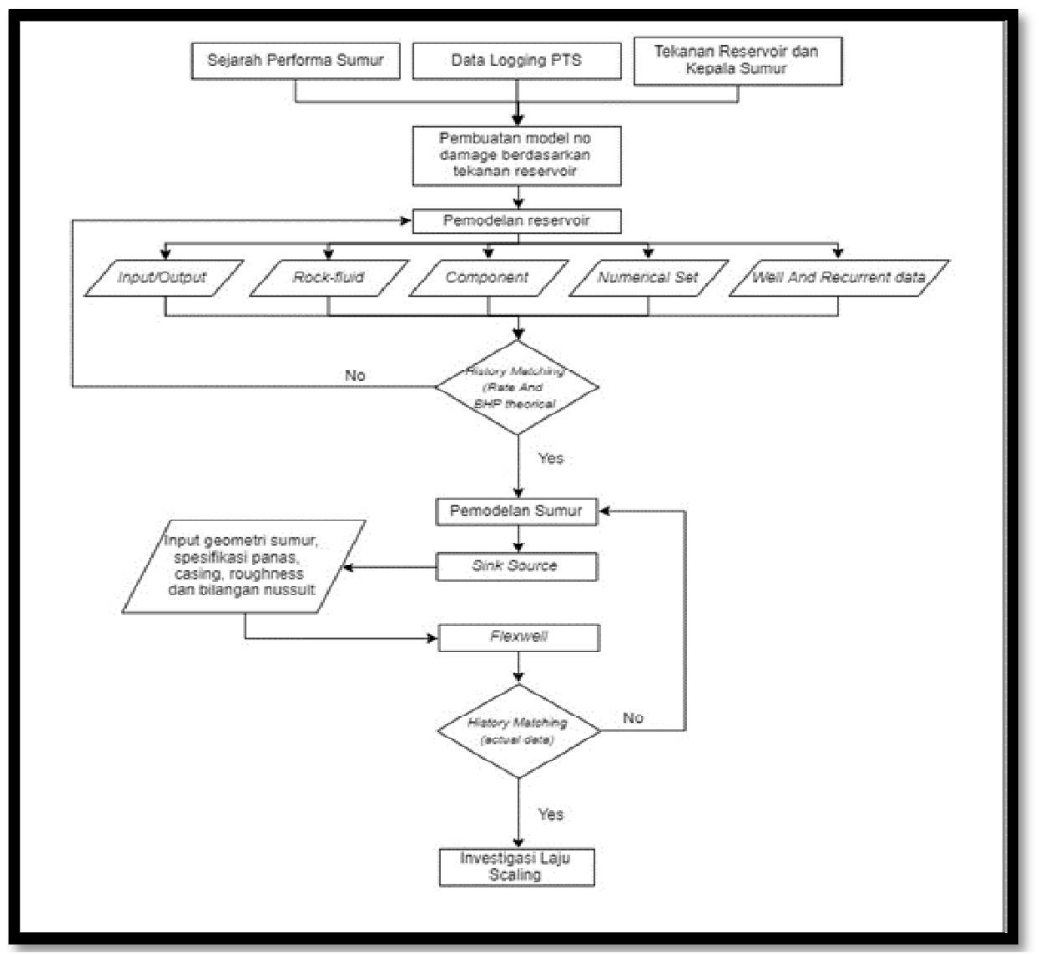

Figure 1: Research Methodology

\section{Basic Theory}

One of the causes of the drastic decrease in production is the presence of scale in the wellbore. Scale is a solid deposition formed from chemical precipitation of liquid composition in geothermal reservoirs. This solid deposition reduces the diameter in the wellbore (casing) and the pipe in the production facility.

\subsection{Silica Scale}

In addition to calcite, the type of scale that is also very commonly found in geothermal wells is scaling silica. Unlike calcite, silica scaling is usually found in high-temperature geothermal systems. In the reservoir, the concentration of silica in geothermal fluid is controlled by the solubility of quartz which rises as the temperature rises. In geothermal reservoir rocks and surrounding areas contain a lot of quartz and will be dissolved in hot water in the reservoir. Above $230^{\circ} \mathrm{C}$ under certain conditions, quartz is at equilibrium between solid forms or as a solute. Following are the reactions of quartz and water which form silica acid:

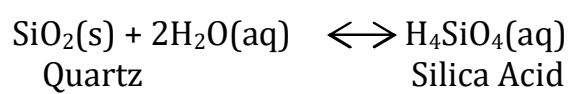

Under equilibrium, the reaction depends on temperature by following the equation:

$\log \mathrm{C}=-13109 / \mathrm{T}+5.19$

Note: $\mathrm{C}=$ Silica Concentration, $\mathrm{mg} / \mathrm{kg}$

$\mathrm{T}=$ Absolute Temperature, $\mathrm{K}$

The above equation applies at temperatures between $0^{\circ} \mathrm{C}$ to $250^{\circ} \mathrm{C}$. The silica solubility at saturated water vapor pressure reaches a maximum of around $340^{\circ} \mathrm{C}$ in pure water. The equation for quartz solubility from $20^{\circ} \mathrm{C}$ to $30^{\circ} \mathrm{C}$ is given by Fournier (1986):

$\mathrm{t}=-42.196+0.28831 * \mathrm{C}-3.6685 \times 10-4 * \mathrm{C} 2+3.1665 \times 10-7 * \mathrm{C} 3+77.034 * \log \mathrm{C}$

Note: $\mathrm{t}=$ Temperature, ${ }^{\circ} \mathrm{C}$

$$
\mathrm{C}=\text { Silica Concentration, } \mathrm{mg} / \mathrm{kg}
$$

Like quartz, amorphous silica solubility is also influenced by salinity and pH. If salinity increases, the amorphous silica solubility decreases (Chen and Marshall, 1982). At low concentrations (salinity $<0.1 \mathrm{~m}$ ), the effect of salinity becomes small (Brown, 1998). Amorphous silica solubility increases sharply when the fluid is alkaline (high pH), but for fluids that are neutral and acidic the effect of pH becomes very small (Henley, 1983).

\subsection{Reservoir Modelling Using CMG}

CMG 2002.10 is a reservoir simulation program created by Computer Modeling Group Ltd. This simulation program is used to do reservoir simulation. This program can be used for single-phase, two-phase or multi-phase reservoirs and can also be used to make simulations with two dimensions or three dimensions.

The wellbore simulation can be used to model the physical behavior of geothermal wells using CMG-Stars software. The simulation starts at the lowest feedzone with initial pressure. Flowrate and temperature depend on parameters of the given feed zone. With this information, all thermodynamic properties can be calculated, as well as expressions for changes in pressure and enthalpy with elevation. Various numerical methods can then be used to calculate conditions iteratively in the next step in the wellbore. 


\subsection{Well Modeling}

Well Modeling consists of three steps namely Sink/Source, Semi-Analytical Wellbore Model and Flexwell. This drill hole model was taken from CMG Training - Advanced Wellbore Model using STARS. Each step of the wellbore modeling has a variety of purposes to determine the condition of the wellbore.

\subsection{Sink Source}

Sink Source is modeling the wellbore in this model. The purpose of the Sink Source is to produce fluid and heat sources from the model. Matching reservoir history for pressures, gas rates, liquid rates, and enthalpy is also affected by the source generated.

\subsection{Semi Analytical Wellbore Model}

The function of the SAM is to calculate the pressure drop and heat loss. Basic principles of vertical well flow such as momentum equations and energy equilibrium are solved for each section of the wellbore in the calculation SAM. The most important parameters are pressure and enthalpy as the main variables. The flow pattern determined based on the fluid velocity and the slope of the pipe.

\subsection{Flex well}

Modeling wells using the most complex CMG software is using the Flexwell feature. Flexwell has ability to simulate complex well.

The simulated Flexwell is accurately processed to model complex wells related heat transfer, fluid flow in the well and its interaction with reservoir, which cannot be modeled by Sink-Source model. FlexWell models various well complexes configurations, including parallel/concentric tubing strings, inflow/outflow and packer, temperature and pressure interactions between each element of the wellbore and reservoir. In addition, flexwell wells are calculated independently from reservoir grid. Numeric parameters such as norm and converge of numset are used by flexwell wells.

\subsection{Reservoir History Matching}

The History matching process consists of matching production history and reservoir pressure between the model simulation results and theoretical and actual data. Actual \& theoretical data on production. reference depth of this reservoir pressure is the first part of perforation layer from surface. If data are not provided, volumetric rate of liquids and gases can be assumed with homogeneous correlations.In this history matching process, the first thing to do is to change the production rate data in $\mathrm{Kg} / \mathrm{s}$ to volumetric $\mathrm{m}^{3} /$ day which is done using Macro-excel by considering the depth and pressure of the major feedzone reference.

\section{Case Study: Modeling Formation Of Silica Scale Deposition On R-5 Earth Heat Welding Wayang Windu Field}

Wayang Windu geothermal field well is a two-phase steam well drilled in 1997. This well has a depth of 2306 mMD and is a directed well that has a two-phase target area in the central Wayang Windu field. This well has an initial production rate of $109.5 \mathrm{~kg} / \mathrm{s}$ with an elastic value of $1574.5 \mathrm{kj} / \mathrm{kg}$ at WHP $12.1 \mathrm{barg}$. But on the way, the production of this well was not as expected, in 2014 the production rate of the well reached $26.4 \mathrm{~kg} / \mathrm{s}$. From the results of the geochemical analysis of the R-5 well in May 2014, the SiO2 concentration of the production fluid was $639.36 \mathrm{ppm}, \mathrm{Cl}$ concentration of $16875 \mathrm{ppm}$, and silica saturated index (SSI) of the R-5 well reached 1.78. so that it can be indicated experiencing silica scaling.

\subsection{Reservoir Modeling Using CMG STARS}

The units of the parameter results used in simulation are determined, there are 3-unit choices available in this software namely SI, Field and Lab. author determines the SI unit for this modeling because the production data and Pressure Temperature Spiner Survey data are generated in the SI Unit. Properties of porosity, permeability and saturation are assumed to be homogeneous in this simulation. Porosity value based on previous research and average value in dynamic reservoir modeling in this well is 0.07 . Permeability range is quite high in this geothermal field. Permeability values of ki, kj, and kk are discussed further in the sensitivity analysis. Water saturation in simulation is set with a value of 0,15 .

\begin{tabular}{|c|c|}
\hline Porosity & $\mathbf{0 . 0 7}$ \\
\hline Horizontal Permeability (I, J) & 100 \\
\hline Vertical Permeability (K) & 50 \\
\hline Gas Saturation & 0.3 \\
\hline Water Saturation & 0.15 \\
\hline Oil Saturation & 0 \\
\hline Null Blocks & 1 \\
\hline Volume Modifiers & 1000 \\
\hline Water Mole Frac. (WATER) & 0.999892 \\
\hline Water Molfe Frac. (SiO2) & 0.000108143 \\
\hline \multicolumn{2}{|c|}{ Table 1: Data Input Array Properties }
\end{tabular}


After creating a cylindrical grid shape, the next step is to determine the thickness and depth of the layer. In well R5 , the perforation was performed starting at a depth of $800 \mathrm{~m}$ which was then defined as layer 9 by the author. In R-5 well there are 3 feedzones where the major feedzone is at a depth of $800 \mathrm{~m}$ with a thickness of $30 \mathrm{~m}$. The following is the thickness input data from the R-5 well model grid.

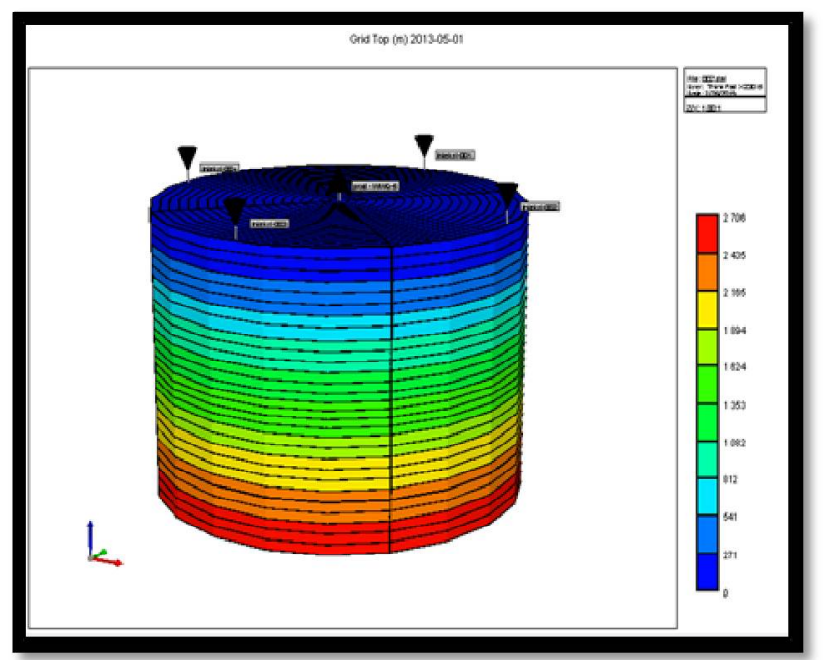

Figure 2: Model Reservoir 3D

\section{2. $R$-5 Geothermal Well Modeling}

Constructing an R-5 well model and the surrounding formations which supply water/steam to the reservoir and also affect the heat transfer between the R-5 well and the surrounding formation. In the area of the system built, the authors assume the area of each grid is $20 \mathrm{~m}$ which then multiply 100 Grids to $2000 \mathrm{~m}$ towards the horizontal. While in the vertical direction, this grid is made with a total of 30 grids on the k-grid consisting of 24 grids for wells and 6 artificial grids. The 6 grids are then divided into 3 empty grids and 3 reservoir grids. The purpose of making the artificial grid is to model the geothermal reservoir which includes water supply and heat sources.

\begin{tabular}{|c|c|c|c|c|c|}
\hline \multirow{2}{*}{ Grid } & Produksi & \multicolumn{4}{|c|}{ Injeksi } \\
\cline { 2 - 6 } & $\mathrm{R}-5$ & 1 & 2 & 3 & 4 \\
\hline $\mathrm{i}$ & 1 & 20 & 20 & 20 & 20 \\
\hline $\mathrm{j}$ & 1 & 1 & 2 & 3 & 4 \\
\hline $\mathrm{k}$ & $9-24$ & & & & \\
\hline
\end{tabular}



Figure 3: Cross Section 2D Model Sumur R-5

Production well in this step is perforated on the feedzone grid k 915 . On the other hand, injection wells are defined as having perforations in the artificial grid zone. In the sink source section, several possible well constraint prices are tested in depth. The constraint of BHP data and the flow rate of water and gas wells is done by importing production data. Bottomhole pressure is then maintained as a primary or secondary constraint to achieve results that are deemed appropriate. In the Well Completion menu, it is possible to select desired layer reference in the perforation zone. For history matching, the perforation zone at the very top / first from the top is chosen because it is used as a reference to measure reservoir depth. 


\subsection{Reservoir History Matching}

History matching process consists of matching production history and reservoir pressure between model simulation results and theoretical and actual data. Actual \& theoretical data on production history and reservoir pressure are provided by the company. Reference depth of this reservoir pressure is the first part of Perforation layer from the surface. If data are not provided, volumetric rate of liquids and gases can be assumed with homogeneous correlations.

The data used here is also not actual data on R-5 well production, but theoretical data on production rates produced by the major feedzone at a depth of $800 \mathrm{~m}$ and BHP of $2360 \mathrm{kPa}$. The use of theoretical data is intended to adjust the condition of the R-5 wells in the model without problem scaling.

After the production rate is considered a match, the next step is to match the reservoir pressure at the reference depth with the theoretical reservoir pressure versus time. This step is done to adjust the condition of the model to the original condition of the ability of the reservoir around the R-5 Well.

Figure 4 and Figure 5 are the actual and simulated results of the R-5 well and gas flow rates. Amount of liquid flowing is affected by the relative permeability of each component. Only the relative gas saturation is adjusted because the relative permeability of the gas - oil is not considered in this modeling. Initially, the fluid rate showed unmatched results compared to actual results.



Figure 4: Water Rate Matching Results (Liquid)

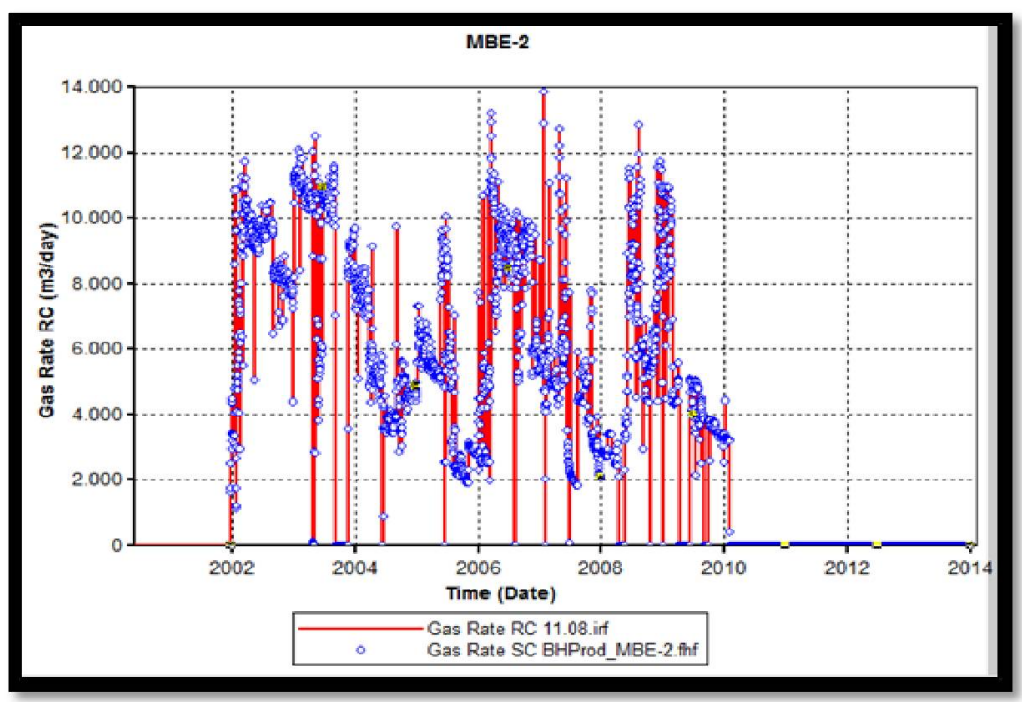

Figure 5: Gas Rate Matching Results (Vapor)

\subsection{Well Sink Source Simulation Results}

Figure 6. and Figure 7. show a graph of pressure \& temperature between the actual data and the relatively suitable model. Therefore, this suitable Sink-Source model continues to be used as the basis for the SAM and Flexwell borehole models. 


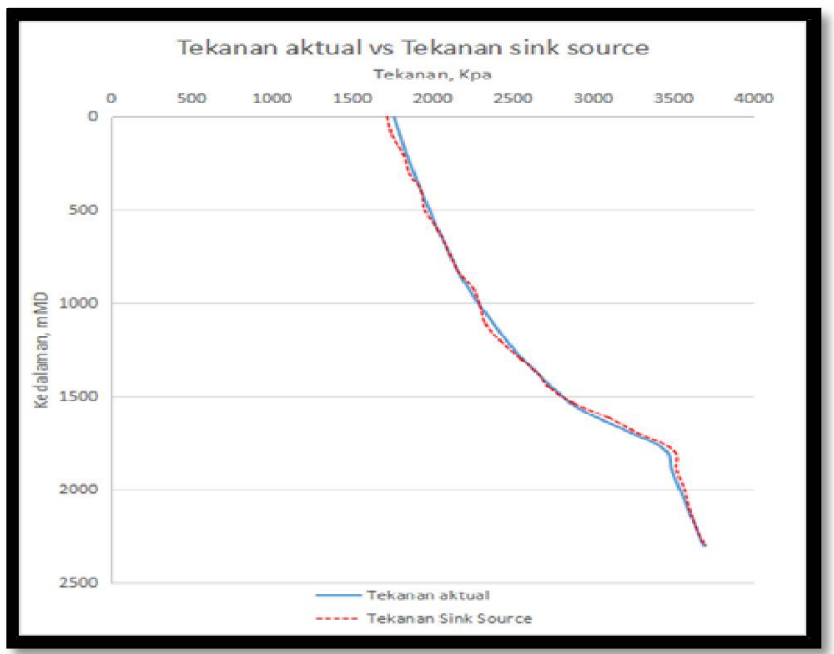

Figure 6: Data Pressure Profile of Sink Source vs Actual Data Simulation

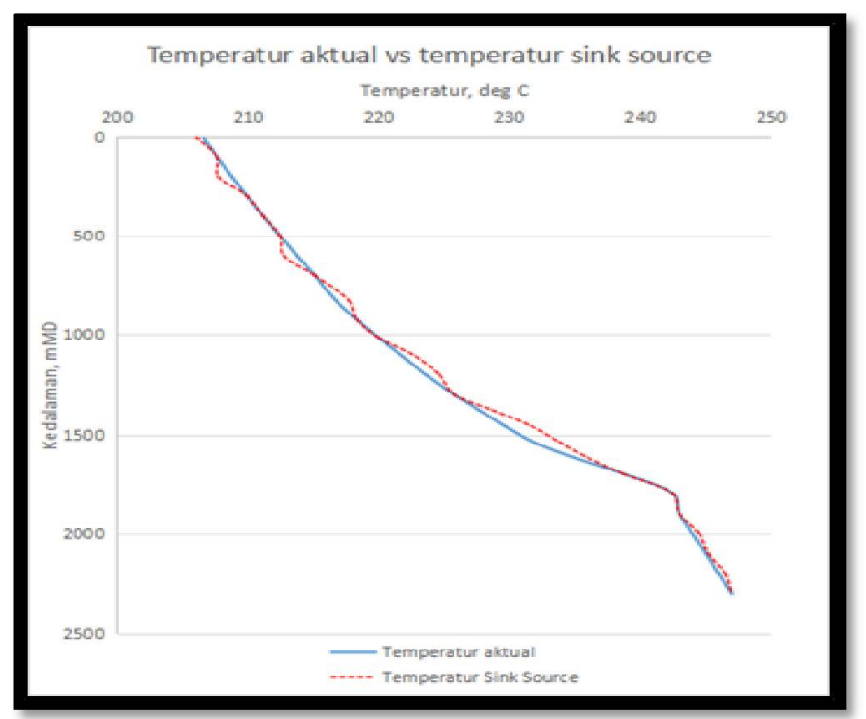

Figure 7: Temperature Profile of Sink Source vs Actual Data Simulation

\subsection{Flexwell Well Simulation Results}

After the Flexwell simulation in RUN, it will get output data as above. Table 3. The above shows the output parameters in the form of simulation data of pressure, temperature, oil saturation, gas / vapor saturation, vapor, and depth of measurement. From the simulation results Sumur X has a steam quality that reaches $83.2 \%$ in the reservoir and experiences several fluctuations in value along the flow towards the surface.

\begin{tabular}{|c|c|c|c|c|c|c|c|c|}
\hline \multirow[b]{2}{*}{ Freswere (Hog) } & \multirow[b]{2}{*}{ Tequeratura(s) } & \multicolumn{4}{|c|}{  } & \multirow[b]{2}{*}{ Desthil(m) } & \multirow[b]{2}{*}{ lengthi(a) } & \multirow[b]{2}{*}{ Ferforation } \\
\hline & & Water Saturatilon & 041 Saturation & toss futuration & Quality(s) & & & \\
\hline mes.s. & $218 . m$ & a. S1 $_{1} 17$ - & o. anow & อ.พมผs & as. & atow & 10. & $1,1,1$ prod . \\
\hline 200.6 & มแล 255 & 4.987R: - 02 & 0,60100 & 0.99072 & 99,9101 & 150,100 & wiwo & $1,1,2$ 'pos . \\
\hline 2030.4 & 219.831 & 1. 16antit-at & 0. & e. $24 \times 55$ & \$5. But & 30.600 & \$. & $1,1,9$ prod - \\
\hline 240.12 & $219 . \mu$ & 1. Mostat a & 1.6000 & C.4hos & 11.\%9 & 30.64 & 4W. ․ㅐ & $1,1,4$ HFod \\
\hline 210 & 200,102 & 6. askalini-at & 0.0000 & 0.9231 & \$3, 444 & sha, 400 & 60,000 & $1,1,3$ mod - \\
\hline $2393 . x$ & 229.679 & th 674964 - -41 & 8.wows & $0.93 \% 54$ & M. S4t & $5 \%$. 1 \% & Han & $1,1,5,1+2$ \\
\hline МMs.3 & $2 n .17$ & 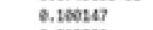 & 0,00000 & onass & 43, 2kat & $6 \omega, \infty \infty$ & m, & $1,1,7$ and \\
\hline 2440.16 & $27 . M 5$ & c.21558 & a. whw & a.rann & หม.21 & 769.600 & Bas.w & $1,1,3, \mathrm{pd}$. \\
\hline 240.77 & $2 n .104$ & 0.21915 & 0.6000 & 0.76045 & 11, \%6 & Bn, & 9x.6\% & $1,1,9$ ind. \\
\hline 2400.48 & 220.693 & 6.245514 & 6. whow & D. & 11. bis & 909.60 & 13is.40 & $1,1,1$ in prest \\
\hline 812,4 & 20,14 & 4,248447 & 6, & 9.7415! & n1, 197 & 161.6 & 146, & $1,1,11$ ond \\
\hline 25.70 & 223.83 & 6.24892 & 0.606s & 6.75117 & ส1. $35 n$ & 1155 .69 & $12 \$ 2.60$ & $1,1,12$ prod \\
\hline 259.27 & 224.144 & 424157 & 6.60\%0 & Q.75496 & 91,9157 & 129959 & 127,6 & $1,1,13$ 'pul \\
\hline 호곡 & $M_{0} \mathrm{NI}_{1}$ & 4. v1Yosit -an & 0 . & อ. - . & $43,46 \%$ & 1136 & 1976 & $1,1,14$ prod \\
\hline 34.5 & $2 \mathrm{~B} .18 \mathrm{~s}$ & 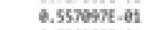 & d. Whow & 6.94454 & 19.585i & 1445.8 & 1455.60 & $1,1,15$ pares \\
\hline $31 \mathrm{sin}$ & $25, k e$ & 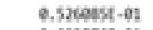 & 0,0060 & e.ming & 43, avis & 1904, 59 & $15,4,8$ & $1,1,16, p \times a$ \\
\hline MMA.S & 28.495 & 6.6how - $4 \mathrm{~A}$ & a.wow & $6.996 \mathrm{n}$ & 3.4857 & 157.9 & 1613.6 & $1,1,1\rangle$, prod \\
\hline x4. & $2 W_{i}, \mathrm{Kn}_{2}$ & aws & $0.6 \times 60$ & 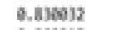 & 12, ws & 164,60 & $16 \omega, \omega$ & $1,1,11$ pros \\
\hline Ha. 13 & 20.835 & d.19hes & G. & 0.860215 & 6. & 1745.49 & $17 \% .6$ & $1,1,14$ prod \\
\hline$m .3$ & $\left.2 n_{1}\right)$ & 4, 440151 -6h & 6. & 6.MMA & 4,4n & 1H4, & 1Wm, & $1,1,2$ cond \\
\hline$m 1.6$ & 238.65 & o. wowe & 0.nowe & 1.060 & sy.ph & 147.59 & 196.60 & $1,1,21$ pres \\
\hline 275,44 & 242.655 & 0.40000 & 0. .0000 & 1.96000 & 13,9709 & $\log _{4} 9$ & 200,6 & $1,1,22 \mathrm{mas}$ \\
\hline 270.67 & $24.4 n$ & 0.20000 & a. .00000 & 1.0060 & ss.wos & 2149.49 & $2 \times 0.60$ & $1,1,23$ press \\
\hline 204.76 & 24.39 & 0.6000 & Q.60\%o & $1.600 \%$ & $33,97 \%$ & 258.6 & 200, & $1,1,24$ pross \\
\hline
\end{tabular}

Table 3: Output Flexwell Well Simulation 


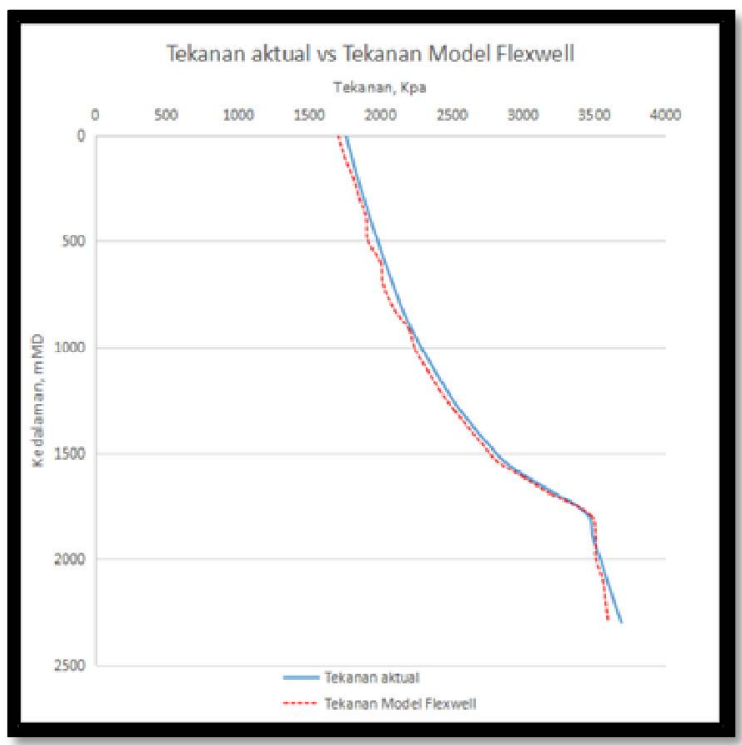

Figure 8: Pressure Profiles of Flexwell vs. Actual Data Simulation Data

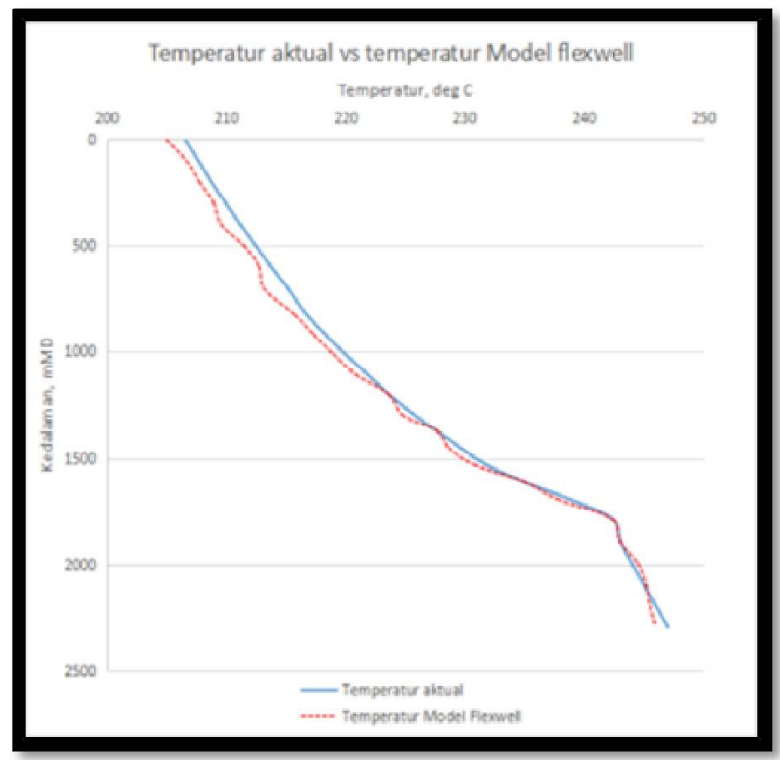

Figure 9: Temperature Profiles of Flexwell vs. Actual Data Simulation Data

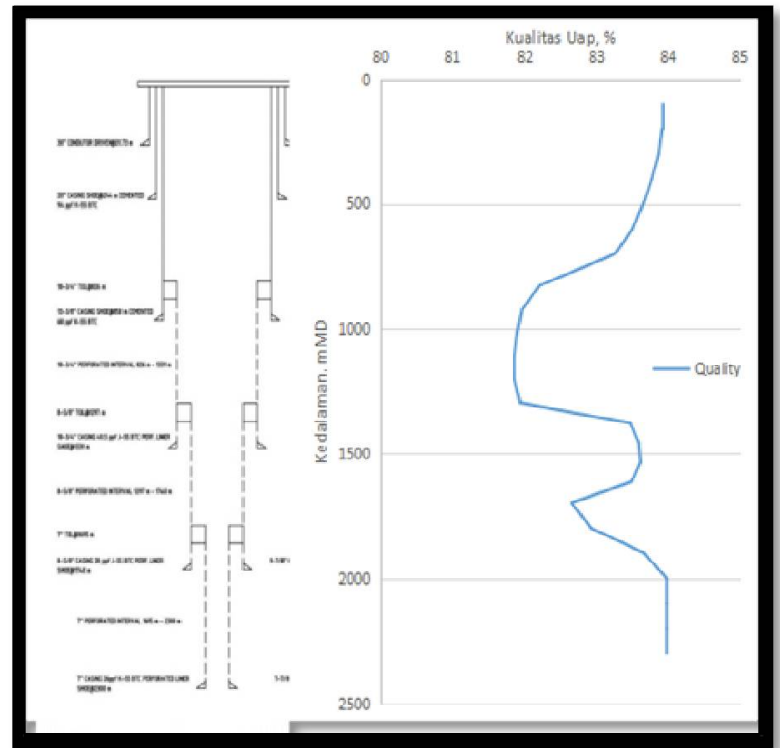

Figure 10: Steam Quality from Flexwell Simulation Result 
Changes in steam quality along the flow are due to heat loss and pressure processes that adjust the feedzone area as well as from heat transfer between the casing and the formation.

\subsection{Identification of Scaling Rate by Using the Flexwell Feature in Wells}

Scale deposition output results in September 2014 scale formed along the wall of the well, where the formation of the scale is most quickly seen at a depth of 850 mMD which covers 2,29971\% of the original diameter of Sumur X. This deposition occurs because of the presence of a boiling zone at that depth and the process of condensation then re-boiling along the fluid flow to the surface. The process of settling the scale also affects the flow patterns that occur along the well, seen from the picture above in each month the flow patterns that occur differ.

\begin{tabular}{|c|c|c|c|c|c|c|c|}
\hline \multicolumn{8}{|c|}{$\begin{array}{l}============ \pm \text { INFORMATIONAL (from subroutine: FLWFRIC) }=============== \\
\text { Counter-current flow in well 'prod - WWQ- } 5 \text { '. Used correlation is not valid. } \\
\text { slip between gas and liquid phases is not calculated. }\end{array}$} \\
\hline \multicolumn{2}{|c|}{$\operatorname{delP}(\mathrm{kPa})$ Wall(Ins, Cem)_Res (day-C/J) } & \multirow{2}{*}{$\begin{array}{l}\text { Fluid_Res (day-C/J) } \\
0.165880 E-09\end{array}$} & \multirow{2}{*}{$\begin{array}{r}\text { Slip } \\
0.999528\end{array}$} & \% Solid Flow & Flow_Regime & \multirow{2}{*}{ Reynolds } & Perforation \\
\hline $0.100227 \mathrm{E}-01$ & $91 \quad 0.370287 \mathrm{E}-08$ & & & $0.241047 \mathrm{E}-02$ & GAS & & 1,1,1 prod - WWQ \\
\hline 20.7224 & $0.370287 \mathrm{E}-08$ & $0.164968 \mathrm{E}-09$ & 1.00000 & $0.531127 \mathrm{E}-02$ & TURBULENT_SPHS & 145070. & $1,1,2$ prod - WWQ \\
\hline 20.9145 & $0.370287 \mathrm{E}-08$ & $0.164728 \mathrm{E}-09$ & 1.00000 & $0.217795 \mathrm{E}-02$ & TURBULENT_SPHS & 142862. & $1,1,3$ prod - WWQ \\
\hline 21.1176 & $0.370287 \mathrm{E}-08$ & $0.159904 \mathrm{E}-09$ & 1.00000 & $0.278543 \mathrm{E}-02$ & TURBULENT_SPHS & 140649. & $1,1,4$ prod - WWQ \\
\hline 21.3288 & $0.370287 \mathrm{E}-08$ & $0.153108 \mathrm{E}-09$ & 1.00000 & $0.292082 \mathrm{E}-02$ & TURBULENT_SPHS & 144846. & $1,1,5$ prod - WWQ \\
\hline 21.5422 & $0.370287 \mathrm{E}-08$ & $0.147734 \mathrm{E}-09$ & 1.00000 & $0.362218 \mathrm{E}-02$ & TURBULENT_SPHS & 145972. & $1,1,6$ 'prod - WWQ \\
\hline 21.7613 & $0.370287 \mathrm{E}-08$ & $0.143508 \mathrm{E}-09$ & 1.00000 & $0.577239 \mathrm{E}-02$ & TURBULENT_SPHS & 143068. & $1,1,7$ 'prod - WWQ \\
\hline 24.8879 & $0.293878 \mathrm{E}-08$ & $0.989886 \mathrm{E}-10$ & 1.00000 & 2.29971 & TURBULENT_SPHS & 127437. & $1,1,8$ prod - WWQ \\
\hline 24.5040 & $0.196380 \mathrm{E}-08$ & $0.100581 \mathrm{E}-09$ & 1.00000 & $0.666663 \mathrm{E}-10$ & TURBULENT_SPHS & 131993. & $1,1,9$ 'prod - WWQ \\
\hline 21.2324 & $0.196380 \mathrm{E}-08$ & $0.818260 \mathrm{E}-10$ & 1.00000 & $0.857271 \mathrm{E}-10$ & TURBULENT_SPHS & 200049. & $1,1,10$ prod $-W W$ \\
\hline 21.4401 & $0.196380 \mathrm{E}-08$ & $0.770969 \mathrm{E}-10$ & 1.00000 & $0.942559 \mathrm{E}-10$ & TURBULENT_SPHS & 206038. & $1,1,11$ prod - WW \\
\hline 21.6602 & $0.196380 \mathrm{E}-08$ & $0.734901 \mathrm{E}-10$ & 1.00000 & $0.970146 \mathrm{E}-10$ & TURBULENT_SPHS & 207287. & $1,1,12$ prod - WW \\
\hline 22.0350 & $0.194313 \mathrm{E}-08$ & $0.496028 \mathrm{E}-10$ & 1.00000 & $0.178198 \mathrm{E}-09$ & TURBULENT_SPHS & 182481. & $1,1,13$ prod - WW \\
\hline 20.6619 & $0.241105 \mathrm{E}-08$ & $0.494350 \mathrm{E}-10$ & 1.00000 & $0.555484 \mathrm{E}-16$ & TURBULENT__SPHS & 246169. & $1,1,14$ prod - WW \\
\hline 18.9724 & $0.241105 E-08$ & $0.495548 \mathrm{E}-10$ & 1.00000 & $0.595602 \mathrm{E}-16$ & TURBULENT_SPHS & 263575. & $1,1,15$ prod - WW \\
\hline 19.1000 & $0.241105 \mathrm{E}-08$ & $0.524369 \mathrm{E}-10$ & 1.00000 & $0.756448 \mathrm{E}-16$ & TURBULENT__SPHS & 263974. & $1,1,16$ prod - WW \\
\hline 19.2150 & $0.241105 \mathrm{E}-08$ & $0.577069 \mathrm{E}-10$ & 1.00000 & $0.708013 \mathrm{E}-16$ & TURBULENT_SPHS & 263117. & $1,1,17$ prod - WW \\
\hline 19.6819 & $0.232284 \mathrm{E}-08$ & $0.655929 \mathrm{E}-10$ & 1.00000 & $0.130362 \mathrm{E}-15$ & TURBULENT_SPHS & 261477. & $1,1,18$ prod - WW \\
\hline 22.4799 & $0.189957 \mathrm{E}-08$ & $0.685375 E-10$ & 1.00000 & $0.222747 \mathrm{E}-13$ & TURBULENT_SPHS & 253292. & $1,1,19$ prod - WW \\
\hline 24.9247 & $0.189957 \mathrm{E}-08$ & $0.953036 \mathrm{E}-10$ & 1.00000 & $0.221996 \mathrm{E}-13$ & TURBULENT_SPHS & 228574. & $1,1,20$ prod - WW \\
\hline 25.0645 & $0.189957 \mathrm{E}-08$ & $0.134591 \mathrm{E}-09$ & 1.00000 & $0.131104 \mathrm{E}-13$ & TURBULENT_SPHS & 188205. & $1,1,21$ prod - WW \\
\hline 25.2377 & $0.189957 \mathrm{E}-08$ & $0.191956 \mathrm{E}-09$ & 1.00000 & $0.585779 \mathrm{E}-14$ & TURBULENT_SPHS & 143040. & $1,1,22$ prod $-W W$ \\
\hline 25.1565 & $0.189957 \mathrm{E}-08$ & $0.308191 \mathrm{E}-09$ & 1.00000 & 1.61178 & TURBULENT_SPHS & 89286.7 & $1,1,23$ prod - WW \\
\hline 24.6337 & $0.191857 \mathrm{E}-08$ & $0.438905 E-09$ & 1.00000 & 1.26938 & GAS & 41322.8 & $1,1,24$ prod - WW \\
\hline
\end{tabular}

Table 4: Flexwell Simulation Results in September 2014

Figure 11. is the result of scale deposition output in Sumur X on the flexwell feature in inches. The simulation results are then adjusted to the scale assessment that has been carried out at the Geothermal XT Ltd. Geothermal Field. At scale assessment, scaling begins to form at a depth of $825 \mathrm{~m}$ which is the top of the 10310 " liner, and at a depth of 2230 $\mathrm{m}$. The following is shown in Figure 12. is an illustration of the scaling rate at R-5 wells between August $2014-$ April 2015.

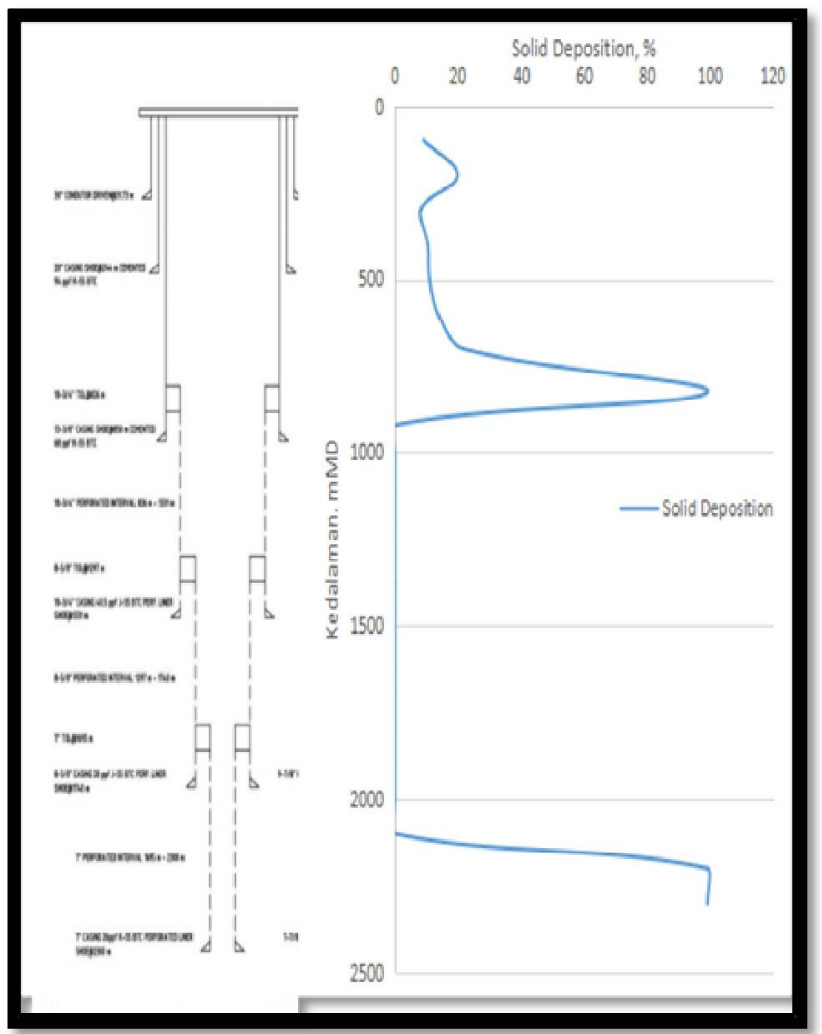

Figure 11: Thick Scale Deposition on

Liner \& Well Casing 




Figure 12: Illustration of Silica Deposition Rate in Wells

The fastest deposition occurred at depths of $825 \mathrm{~m}$ and $2230 \mathrm{~m}$ with solid concentrations reaching $1.23 \mathrm{E}-6 \mathrm{Kg} . \mathrm{m} 3$ / month in the period March 2014 - July 2014 and increasing in the period August 2014 - April 2015 to 1.87E-6 Kg.m3 / month. This process occurs faster in the boiling zone of the feedzone between $825 \mathrm{~m}-2230 \mathrm{~m}$ depth. The mechanism of silica scaling formation along the well flow is caused by the condensation process due to heat loss and also re-boiling that occurs due to heat transfer along the pipe (heated pipe), but scaling at the flow condition the process is not faster than scaling in the boiling zone in perforation zone. The silica deposition that occurred then made the diameter of the wellbore narrowed previously by $0.26 \mathrm{~m} /(103 / 4$ ") to only about $0.026 \mathrm{~m}$ (1") in April 2015 or reduced by $99 \%$ of the original diameter if not immediately carried out in the program well stimulation.

\section{Discussion}

R-5 well is a two-phase steam well drilled in 1997. This well has a depth of 2306 mMD and is a directed well that has a two-phase target area in the central Wayang Windu field. This well has an initial production rate of $109.5 \mathrm{~kg} / \mathrm{s}$ with an Elthalpy of $1574.5 \mathrm{kj} / \mathrm{kg}$ at WHP 12.1 barg. In 2014 the production rate of wells reached $26.4 \mathrm{~kg} / \mathrm{s}$. From the results of the geochemical analysis of the R-5 well in May 2014, the SiO2 concentration of the production fluid was 639.36 ppm, and the Silica saturated index (SSI) of the R-5 well reached 1.78. so that it can be indicated experiencing silica scaling. In-depth research on the rate of settling of the scale in February 2014 to April 2015, this research was carried out because if we can find out the deposition rate and the formation mechanism of the scale.

Constructing an R-5 well model and the surrounding formations which supply water / steam to the reservoir and affect the heat transfer between the R-5 well and the surrounding formation. This model was built using a cylindrical grid type because the grid will create a balanced heat flow and pressure in the R-5 well.

Fluid in the reservoir model is defined by inputting the data of chemical components contained in the R-5 Well reservoir. These components are very important in research regarding the investigation of the rate of scaling in the well flow, because in CMG-STARS, a stoichiometric chemical reaction can be carried out. Therefore, the authors input $\mathrm{H} 2 \mathrm{SiO} 4 \mathrm{data}$ under conditions dissolved in water, and then react to produce SiO2 in the solid phase and H2O in the liquid phase, the authors also define the content of NCG (Non-condensable gas) in the form of CO2 and H2S. Data on liquid density, critical pressure, critical temperature of the components are then inputted.

History matching is done here is the history matching of the production rate of the well model with the theoretical well production rate where there is no scaling. This is intended to adjust the condition of the model to its original condition. After simulating the production rate and the bottom hole pressure at the reference depth is considered appropriate then it can be done well modeling. Bottom hole pressure in the initial conditions in the actual well data is $2366 \mathrm{kPa}$ and in the model is $2201.96 \mathrm{kPa}$, while the initial volumetric vapor rate data and the model show similarities are $383550 \mathrm{~m}^{3} /$ day or $52 \mathrm{Kg} / \mathrm{s}$.

Sink Source modeling is done to be the basis of the Well model, the output of the Sink Source model is only in the form of temperature and pressure data along the well to the surface. In this model things such as casing diameter and roughness cannot be defined. Only the location of the perforation point can be defined. The results of temperature and pressure simulation along the flow to the surface of the well are then matched with the actual data obtained after logging PTS, after the data is compatible, the Sink Source Well model can be used as the basis of the SAM and Flexwell modeling. This Flexwell modeling was first carried out by inputting property data from the casing geometry and its parameters such as the Heat Conductivity of the well wall and cement, pipe roughness, Nusselt number and well diameter. In the parameters of the heat conductivity of the cement, casing, this flexwell feature will eventually produce data from fluid flow patterns along the well, temperature, pressure, water saturation, steam saturation, steam quality and solid deposition. From the Flexwell model it is found that the steam quality of $83.97 \%$ at the bottom of the well and $83.92 \%$ on the surface, the quality of this steam fluctuates along the well which is caused by the condensation process and also Flashing so that the flow pattern changes throughout the time function of the production well caused by the deposition of scale on the wall 
of the R-5 well. Pressure losses along the well flow can also be analyzed using the output from Flexwell, pressure losses in the casing section above the perforation zone to the surface range between prices $48-51 \mathrm{kPa} / 100 \mathrm{~m}$ vertically.

From the results of the simulation carried out, the well where the formation of Silica scale in the Well occurred along the well in a time function, the fastest deposition occurred at depths of $825 \mathrm{~m}$ and $2230 \mathrm{~m}$ with solid concentrations reaching 1.23E-6 Kg.m³/month in the March period 2014 - July 2014 and increased in the period August 2014 - April 2015 to $1.87 \mathrm{E}-6 \mathrm{Kg} \cdot \mathrm{m}^{3} / \mathrm{month}$. Silica deposition that occurs then causes the diameter of the wellbore to shrink from the previous $0.26 \mathrm{~m} /(10$ 3/4 ") to only about $0.026 \mathrm{~m}$ (1") in April 2015 or decreases by $99 \%$ from the original diameter if not immediately carried out in the program well stimulation.

Stimulation program carried out in order to clean scaling of wells is by way of well washing and matrix acidizing, well washing is a treatment carried out.

\section{Conclusions}

- The reservoir model is created using CMG-STARS software to simulate the well condition with the area of the system being built is $2000 \mathrm{~m}$ in the horizontal direction and $3100 \mathrm{~m}$ in the vertical direction. In the vertical direction, this grid is made with a total of 30 grids on the k-grid consists of 24 grids for wells and 6 grids as reservoirs.

- Modeling wells using the Simple Analytical Model (SAM) obtained steam quality ranging from $83.97 \%$ at the bottom of the well and $83.92 \%$ at the surface.

- The history matching process of the model is quite good where, the bottom hole pressure in the initial conditions in the actual well data is $2366 \mathrm{kPa}$ and in the model is $2201.96 \mathrm{kPa}$, while the initial volumetric vapor rate data and the model show similarities are $383550 \mathrm{~m}^{3} /$ day or $52 \mathrm{Kg} / \mathrm{s}$.

- Based on the results of the simulation conducted, the difference in roughness casing and liner production of geothermal wells R-5 causes the formation of silica at a depth of $825 \mathrm{~m}$ and $2230 \mathrm{~m}$ has the highest settling rate.

- The scaling concentration rate in the R-5 Well between March 2014 - July 2014 is $1.23 \mathrm{E}-6 \mathrm{Kg} \cdot \mathrm{m}^{3} / \mathrm{month}$, and has increased in August 2014 - February 2015 at a rate of $1.87 \mathrm{E}-6 \mathrm{~kg} \cdot \mathrm{m}^{3} / \mathrm{month}$ so that it almost covers $99 \%$ of the well diameter.

\section{Acknowledgement}

Thanks to Geothermal Team UPN "Veteran” Yogyakarta: M.Th. Kristiati EA, S.T., M.T., Ir. Bambang Bintaro, MT., Dewi Asmorowati, S.T., M.Eng..

\section{References}

i. $\quad$ A. Hasan and C. Kabir, "Fluid Flow and Heat Transfer in Wellbores," SPE, Richardson, Texas, 2002.

ii. A. Hasan and C. Kabir, "Modeling Two-Phase Fluid and Heat Flows in geothermal wells," Journal of Petroleum Science and Engineering. Elsevier, 2010.

iii. Bogie, I., Kusumah, Y. I., \& Wisnandary, M. 2008: “Overview of The Wayang Windu geothermal field, West Java, Indonesia". Geothermics.

iv. Bjornsson, S. Bodvarsson, G. 1988: "Reservoir Rock Properties of Existing Geothermal Fields"

v. CMG. 2009: "User's Guide STARS Advanced Process and Thermal Reservoir Simulator" Vol 1 \& 2, Computer Modelling Group Ltd. Calgary, Canada.

vi. CMG. 2013: "Advanced Wellbore Modelling Using CMG-STARS". Computer Modelling Group Tutorial. Calgary, Canada.

vii. Mulyadi. Ashat, A. 2011: "Reservoir Modeling of the Northern Vapor-Dominated Two-Phase Zone of the Wayang Windu Geothermal Field, Java, Indonesia" Thirty-Sixth Workshop on Geothermal Reservoir Engineering Stanford University. Stanford, California.

viii. Nicholson, K. 1993: "Geothermal Fluids Chemistry and Exploration Techniques". School of Applied Sciences the Robert Gordon University. Scotland, United Kingdom.

ix. $\quad$ Nirzami, M. Sutopo. 2013: "Mathematical Modelling of Silica Scaling Deposition in Geothermal Wells," IOP Conf. Ser.: Earth Environ. Sci. 42.

X. Nugroho, Rio. 2015: “Kajian Stimulasi Sumur X-1 dan X-2 di Lapangan Panasbumi Wayang Windu”. Program Magister Panasbumi ITB. Bandung, Indonesia.

xi. Saptadji, N. 2004: “Teknik Panas Bumi (Geothermal Engineering)”, Department of Petroleum Engineering- Insitute of Technology Bandung. Bandung, Indonesia.

xii. Star Energy. 2015: "Star Energy Geothermal Scaling Assessment Report”. Star Energy Geothermal Ltd.

xiii. Yang, X. Li, W. Guo, L. Liu, X. Feng, H. 2016: "Prediction of CaCO3 Scaling in Water Injection Wellbore. Journal of Applied Thermal Engineering 98. Beijing, China. 